\title{
Countermeasures on the Reform and Development of Pre-school Education in Western China under the Background of New-type Urbanization
}

\author{
Libin Guo \\ Science and Technology Department, Chongqing University of Education, Chongqing 400065, \\ China; \\ guolb@cque.edu.cn
}

\section{Keywords: New-type urbanization; Pre-school education; Countermeasures}

\begin{abstract}
Since the reform and opening, China's pre-school education has made great progress. However, under the background of New-type Urbanization, the development level of pre-school education in the eastern and western regions has become increasingly unbalanced. This article takes Chongqing, the only municipality in the western region, as empirical study, accurately docking difficult problems such as the difficulty of admission and the expensive cost of admission. It proposes some countermeasures, such as the innovation of the institutional mechanism of pre-school education from the demonstration area, the construction of a collaborative innovation community of "government + college + kindergarten", and the promotion of the government purchase services, to provide a useful reference for promoting the reform of the supply side of pre-school education in the western region.

A hundred years of life is based on pre-school learning. In the report of the 19th National Congress, it is clearly required to run pre-school education and strive to ensure that every child can enjoy fair and quality education. To change from a powerful nation of education to a nation of powerful education, China must change from a powerful nation of pre-school education to a nation of powerful pre-school education. However, the objective condition of the current development of pre-school education in China is that the gap between the east and the west is very huge, and the gap between the urban and rural is also very large. This status quo of unbalanced development of pre-school education directly affects educational equity and social equity, which is not conducive to the harmonious development of society and the full realization of a well-off society.

As a national central city with important radiation and driving effects in western China, Chongqing is taken as an empirical study for the reform of pre-school education in the western region, exploring how to return to the essence of education in the context of new-type urbanization, grasp pre-school education from the source, and accurately dock difficult problems such as the difficulty of admission and the expensive cost of admission when implementing the plan of the third-term pre-school education. This article is problem-oriented, with reform as the driving force, starting from three breakthroughs. It can provide some practical references and policy recommendations for promoting the supply-side reform of pre-school education in the western region and narrowing the pre-school education gap between the eastern and western regions.
\end{abstract}

Build a reform and development demonstration zone of national pre-school education, explore the extension of the compulsory education chain, and innovate the system and mechanism of pre-school education in the demonstration area.

Under the background of "the universal two-child policy", the phenomenon of pre-school education differentiation in Chongqing is obvious. "The education quality in rural areas are poor while the cost in city is expensive, and the people are very dissatisfied about it." Pre-school education has become the weakest link in the Chongqing education pattern. Based on the current unfair distribution of high-quality resources in pre-school education and insufficient inclusiveness, it is necessary to build a national reform and development demonstration zone of pre-school education as a breakthrough, and take the lead in innovating mechanisms in the demonstration area to implement innovative supply reform by region, phase, and age, leading pre-school education to achieve new development from point to area.

Sub-regional selection and construction of demonstration zones for pre-school education reform and development.

Guided by the resources of normal school and high-quality kindergartens, the reform and development demonstration areas of pre-school education in line with local characteristics should be selected and constructed 
in the main urban areas of main urban zone of Chongqing, western Yunnan, southeastern Yunnan and northeastern Yunnan. the districts and counties cooperate to provide services such as policy tilt, hardware support, platform support and intellectual information, and actively guide the pilot areas to innovate models and methods. According to different resource endowments, give full play to the driving effect of normal school and high-quality kindergartens, implement the collaborative development project form of "double-choice-order", and explore cooperative innovations such as " normal school + kindergartens, group headquarters kindergartens+ new kindergartens, high-quality kindergartens+ low-quality kindergartens, public kindergartens + Private Kindergarten" to further promote the model innovation and development of the pre-school education reform demonstration zone. Establish a talent pool of pre-school teachers and a unified performance-based pay system for pre-school teachers, which is based on teachers professional title, and promote the salary reform of pre-school teachers in the demonstration area.

Extend the time chain of compulsory education in the demonstration area in stages.

At present, it is not feasible to include all three years of pre-school education in compulsory education. But it is possible to explore the implementation of pre-school education in Chongqing for one year free of charge. That is to say, the regions with higher economic development will go ahead, and the minority and poverty-stricken areas will go backwards. It will be free to popularize pre-school education in stages for one year. That is to say, the regions with higher economic development will go ahead, and the minority and poverty-stricken areas will go backwards. It will be free to popularize pre-school education in stages for one year. Encourage the demonstration areas of pre-school education reform and development in the main city and western Yunnan to take the lead in exploring ways and means of extending compulsory education and implementing free pre-school education. In the demonstration areas of ethnic minorities and poverty-stricken areas in southeastern Yunnan and northeastern Yunnan, a mechanism for raising funds and sharing costs based on municipal financial allocations, social charitable donations and appropriate parental contributions will be established, and a special project for one-year pre-school education (including teacher training of one-year pre-school education) will also be established. Strengthen the integration of pre-school and first- grade and second-grade primary schools, making it a relatively independent lower-level early childhood learning stage, and formulating the curriculum standards and teacher qualification standards for pre-school and primary school first- and second-grade integration. It is necessary to include the teachers for one-year pre-school education in the team of public teachers in primary schools and explore the form of pre-school classes in primary schools in the demonstration area to popularize pre-school education.

\section{Coordinate and plan "kindergarten service" by age.}

The pre-school education stage is divided into two age groups of 0-3 years old and 3-6 years old, and the planning and construction of kindergarten service and pre-school education for children aged 0-3 and 3-6 years old should be integrated into the planning and construction of the demonstration area, a network of kindergarten service and pre-school education based on the demonstration area should be established, and the responsibility of kindergarten for $0-3$ year old children should be clarified to ensure that every family in need can send children to the kindergarten.

Construct a collaborative innovation community of "government + normal school + kindergarten", scientifically develop standards, and plan and build new-type kindergartens and new-type kindergarten teachers from a high starting point.

For the current condition of insufficient exertion advantages of the government, normal schools and kindergartens, the lack of synergy of the "trinity", the inadequate docking of their respective development goals, the collaborative innovation community for substantive cooperation and development of "government + normal school + kindergarten" should be explored and constructed.

The three parties are encouraged to sign a joint strategic cooperation agreement for joint construction and sharing.

Through the cooperation agreement to establish a system for the use of special funds for tripartite cooperation, ensure sufficient investment in supporting funds, and ensure the interaction of the three parties in the normal state. Clearly establish the benchmark for the construction of collaborative innovation community. For example, select 3 to 5 municipal development and reform demonstration zones of pre-school education as pilots, and cooperate rely on the large projects that all three parties are concerned about and participate in. After the pilot has accumulated certain resources and experience, determine it as a benchmark and then carry out 
extensive promotion, and promote the transformation of the "trinity" cooperation results.

Scientifically develop relevant standards to lead the development of kindergartens and kindergarten teachers in the future.

Aiming at the construction needs of kindergartens for future social development, grasp key points of coordination, collaboratively research and publish construction standards of future kindergarten, implement new kindergarten entities with future innovations, leading and promoting the shape transformation and all-round reform and innovation of future kindergartens. Study and formulate the working standards of kindergarten teachers. According to the development stage of different majors, refine the working standards of kindergarten novice teachers, the working standards of skilled novice teachers, the working standards of competent teachers, the working standards of professional teachers and the expert teachers, and then set the basic indicators for kindergarten teachers of professional development at different stages.

Deeply develop cooperation mode and cultivate new types of kindergarten teachers.

Organize a team of experts consisting of normal school teachers, district and county education committees, excellent directors and famous teachers, and establish a network of teaching and research guidance for all kinds of kindergartens covering districts, streets (townships) and communities (villages), and improve the system of responsibility areas on teaching and research guidance. Relying on the collaborative innovation community to carry out the research of pre-school education, the training of teachers, the innovation of teaching system, and the building of teaching team. Improve the integrated training system for kindergarten directors, teachers, health care doctors and childcare workers, and carry out full-time training at different levels five-year a round to provide a solid guarantee for the construction of new kindergarten teachers.

Promote government-purchased services, build pre-school education service areas, and explore new modes of public kindergarten management.

In view of the phenomenon of limited admission quota that the parents have to use relations to walk the back door for children' admission of public kindergartens one year in advance and register for the overnight queues, it is necessary to actively explore and practice the way in which the government purchases educational services from social organizations to meet the needs of public education and build pre-school education service areas, explore public bidding in the service area and entrust the brand institution to hold public kindergartens.

The special funds for the government to purchase pre-school education services are included in the budget, and the management of kindergarten funds is implemented in two lines of income and expenditure. The kindergartens implement the charge standard of public welfare kindergartens, and all types of income are turned over to the government. Kindergarten's entrusted management fees, faculty and staff salaries, average public funds for students and special funds are all included in the budgetary guarantee, and the expenses for large-scale projects such as expansion and maintenance are allocated to the kindergartens in the form of special funds.

The winning bidder implements "management input" for the kindergarten and sends a management team to be responsible for the daily management and operation of the kindergarten. The management team consists of an executive team, a team of experts and a team of faculty and staff. The executive team is the head of the kindergarten and the deputy director. The team of experts is no less than 2 people. The team of faculty and staff consists of employees who have been openly and fairly recruited and established labor contract relationships with the winning bidder according to the approved number of jobs and employment and the salary standard.

Implement the signing of the "Kindergarten Entrusted Management Service Contract" by the street supervisor and the bidding agency and the street office of the kindergarten. The local street office is responsible for daily supervision of care and education, safety and health of the kindergarten. The kindergarten should have a cashier position while the accounting position is in the local street office, to effectively supervise the use of kindergarten funds.

Conduct industry assessments. The education authorities shall formulate the Measures for the Evaluation of Public Kindergartens, consult the local street offices and entrust a third-party professional organization to implement "assessment every year and evaluation every three years" on the management level and the quality of the kindergarten. That is to say, the kindergarten will be assessed once a year. If the annual assessment result is unqualified, the entrusted management service will be terminated immediately. The kindergarten will be fully evaluated every 3 years. After the evaluation, if the entrusted management services provided by the institution meet the requirements, and the entrusted management of the kindergarten will be renewed service 
contract.

\section{Acknowledgement}

Funding: This study was supported by the project 'Future School (infant education)' of National Center For Schooling Development Programme of China (Grant No. CSDP18FC1203)

\section{References}

[1] Feng Wenquan, Xu Songni, Gao Jing, The Causes and Solution of the Unbalanced Development of Pre-school Education in China[J].Journal of Southwest University(Social Science Edition), 2016.11.

[2] Chen Duo, "The Road to Entrepreneurship of Young Entrepreneurs in the New Era" [J]. "Global Business Classics".

[3] Shi Pengshuang, Study on the Balance of Resource Allocation in Pre-school Education in Xixian County[J]. Master's Thesis of Guangxi University, 2014.05.

[4] Liu Qu, the status quo and suggestion of the "Trinity" cooperation mode of government, colleges and kindergartens[J]. Journal of Harbin Vocational and Technical College, 2016.11.

[5] Liu Lei, Ni Xiu, behind the custody of public kindergartens [J]. China Education News, 2016.06. 